\title{
¿QUÉ ES EL CORREO ELECTRÓNICO?
}

\author{
Pgr. CARLOS CHAVEZ DODERO
}

El correo electrónico, también llamado e-mail (electronic mail), es una forma de enviar mensajes, gráficos o cartas electrónicas de un computador a otro. Tanto la persona que envía el correo electrónico, como la persona que lo recibe debe tener una cuenta en un servidor de Internet (necesariamente no tiene porque ser un usuario de la red Internet, se puede enviar correo electrónico a usuarios de otras redes como FIDONET, COMPUSERVE, BITNET, etc., que mediante unas máquinas especiales, llamadas pasarelas o gateways, hacen llegar el correo).

El e-mail fue uno de los primeros servicios que ofreció la red 'ARPANET. Esto no quiere decir que sea un servicio exclusivo de la red Internet. El e-mail es un servicio que ofrece prácticamente todo tipo de redes existentes.

En realidad el e-mail es muy parecido al correo tradicional, aunque tiene varias diferencias que le proporcionan una serie de ventajas muy importantes:

Para enviar el correo tradicional es necesario pagar por cada mensaje que se envía (sellos, sobres, papel, etc.). Sin embargo con el e-mail sólo hay que disponer de una cuenta en una máquina (en ocasiones habrá que pagar si el servidor en la que se tiene la cuenta es privada, y en otras ocasiones el servicio es gratuito) y no hay los gastos antes mencionados.

\begin{abstract}
El e-mail es mucho más rápido que el correo tradicional. Los mensajes electrónicos llegan en cuestión de minutos a cualquier lugar del mundo donde se encuentre el destinatario. La acción se realiza a través de las computadoras, las cuales verifican las direcciones, emiten el mensaje y lo almacenan en un buzón especial del disco duro.
\end{abstract}

En el correo tradicional este proceso suele demorar días, semanas e incluso meses. La copia de un mensaje o una carta electrónica puede ser fácil de distribuirla a varios destinatarios simultáneamente con sólo indicar las direcciones de éstos. En cambio, si queremos hacer lo mismo en el correo tradicional habría que emitir varias copias de la carta y pagar por cada una de ellas.

Otra de las ventajas del e-mail es que su empleo no daña la ecología, pues a difererencia del correo tradicional no necesitamos utilizar papel. El correo electrónico es un documento electrónico, que en caso de querer almacenarlo se guarda en un fichero, con el consiguiente ahorro de papel y en definitiva de árboles y, bosques.

Al principio, el correo electrónico sólo enviaba mensajes de texto con mayor o menor rapidez entre pocos usuarios. En la actualidad es posible enviar todo tipo de datos binarios gracias a un estándar como MIME oUUDECODE. Se pueden incluir como 
parte del mensaje imágenes, sonidos, ficheros binarios, programas ejecutables, etc. Para ello es necesario que tanto el usuario que envía el correo como el que lo recibe, dispongan de un gestor de correo que cumpla o incluya estos estándares.

Una característica importante del e-mail es que si un usuario tiene un acceso limitado a Internet, con su cuenta de correo puede sacar mucho provecho a servicios como el FTP, ARCHIE, LISTAS DE CORREO, etc. Asimismo, para comprobar si el correo ha llegado a su destino sólo basta consultarlo con la máquina, pues cuenta con un buzón especial donde almacena los mensajes.

Otras características del e-mail que le añaden más funcionalidad son:

- Es posible definir ALIAS. Consiste en asociar un nombre, normalmente corto, a una dirección de correo electrónico. Normalmente se suelen definir alias cuando estas direcciones son utilizadas con mucha frecuencia.

- Es posible organizar el correo en CARPETAS. Si el volumen de correo recibido es grande será necesario almacenar ese correo por temas, por usuarios, etc. Sería algo parecido a almacenar ficheros en directorios.

- Podemos retransmitir mensajes que nos llegan hacia otras direcciones de correo.

- Con los sistemas actuales de correo podemos reenviar un mensaje que nos ha llegado. Es decir, respondemos a un mensaje basándonos en el que nos ha llegado, tomando datos de éste.

Hay muchas características que dan mayor funcionalidad a un sistema de correo electrónico, pero éstas son las más habituales. Además dichas posibilidades dependen del software de correo electrónico usado en cada caso.

El correo electrónico, frecuentemente llamado e-mail o mail (palabra en inglés equivalente a correo), es una herramienta que permite enviar y recibir mensajes escritos a otro $u$ otros usuarios en una red de información(Red de Datos). Estos mensajes o "cartas electrónicas" se escriben en una computadora local y se envían a través de las redes de computadoras a sus destinatarios, quienes deben disponer de una dirección de correo electrónico “ (E-mail address) válida.

\section{DIRECCIONES DE CORREO ELECTRÓNICO}

Una dirección de correo electrónico es la forma que tenemos de especificar al programa de correo electrónico, el lugar o persona a la que queremos enviar el mensaje en concreto. La dirección de correo electrónico tiene la siguiente forma básica:

\section{usuario@pc origen.dominio}

Primero se pone usuario, indica el buzón de correo electrónico correspondiente a la persona a la que va destinado el mensaje. Después se coloca un símbolo que se denomina arroba. A continuación escribimos el nombre de la máquina o nombre del servidor donde tiene cuenta el usuario y por último anotamos un punto seguido del tipo de dominio al que pertenece la máquina. Todo lo que va después de la arroba se le suele llamar nombre completo del dominio del ordenador.

Hay varios tipos de dominios en Internet. Normalmente suelen tener como máximo 3 letras que los identifican. A continuación explico algunos: 
- com: para un negocio o una empresa internacional.

- edu: para una Universidad o centro de educación.

- org: para una organización no comercial.

- gob: para una agencia u oficina gubernamental.

- mil: para una institución militar.

- net: para una red determinada.

En otras ocasiones se pone un indicativo del país donde está situado el servidor geográficante hablando:

- pe: Perú

- es: España

- ar: Argentina

\section{Protocolos que intervienen en una aplicación de correo electrónico}

El correo electrónico de Internet se implemento originalmente como una función del protocolo FTP. En 1980 dos personajes, Suzanne Sluizer y Jon Postel, realizaron trabajos con un protocolo que luego se llamaría SMPT (Simple Mail Transfer Protocol). Hoy en día se sigue utilizando este protocolo (con algunos avances como es lógico) para la entrega de mensajes entre sistemas de Internet.

El protocolo SMTP fue desarrollado pensando en que los sistemas que intercambiarían mensajes eran grandes computadores, de tiempo compartido y multiusuario que estaban continuamente conectados a la red Internet. Sin embargo con la aparición de los PCs en el mundo de Internet, que tenían una conectividad ocasional, se hizo necesaria una solución para que el correo llegase a estos PCs.
Para solventar esta limitación, en 1984 surgió el POP (Post Office Protocol). Este protocolo, en su especificación inicial, sólo permitía funciones básicas como recuperar todos los mensajes, mantenerlos en el servidor y borrarlos. En sucesivas versiones del protocolo (POP2, la actual versión POP3) se han ampliado las funciones que permiten una mejor gestión del correo.

Estos dos protocolos son los encargados de transportar el correo por toda la red Internet, pero sólo son capaces de transportar mensajes en formato texto ASCIL (Caracteres). Para superar esta limitación se utilizaba hasta hace poco tiempo, programas como el UUEncode y en 1992, surgen las MIME (Multipurpose Internet Mail Extensiones), que permiten el correo electrónico en otras lenguas además del inglés, además sonido, gráficos, vídeo, etc. En la actualidad el estándar MIME es el más usado.

\section{EL CORREO ELECTRÓNICO EN. INTERNET.}

Para poder hacer uso del correo, el usuario tiene que disponer de una aplicación especial llamada de forma genérica programa lector de correo electrónico. En el mercado existe una gran variedad de programas de este tipo: Eudora, PegaSus Mail, Mail OnNet o Microsoft Exchange son algunos ejemplos.

Una vez que el usuario ha establecido la conexión con el proveedor de acceso de Internet, lo único que debe hacer es ejecutar el programa lector y utilizar sus opciones.

Pero, ¿cómo pueden entenderse entre sistemas de ordenadores tan dispares como los que están conectados a Internet? La respuesta es simple, gracias a que el envío de correo está normalizado por el sistema llamado SMTP (Simple Mail Transfer 
Protocol, protocolo simple de transferencia de correo). El SMTP forma parte de la familia de protocolos TCP/IPy define el formato que deben tener los mensajes de correo electrónico y cómo serán manejados estos mensajes por la red.

El SMTP es un protocolo de principios de los años ochenta, por lo que está pensando para enviar mensajes cuyo contenido es exclusivamente texto ASCIL. Esto quiere decir que el SMTP no admite el envío de ficheros binarios; o dicho de otra forma, para SMTP, toda la información que trasmite está compuesta por grupos de 7 bits, cada uno de los cuales representa un carácter alfanumérico.

Con este sistema puede viajar por distintos sistemas informáticos con distintos códigos de caracteres, cuando el mensaje cambia de un sistema informático a otro, SMTP cambia la combinación de 0 y 1 de cada grupo de 7 bits para que siga representando al mismo caracter.

Así nos aseguramos que distintos entornos informáticos, Mac, Minis, PC, etc., intercambien mensajes de correo electrónico sin ningún problema. El inconveniente surge cuando lo que queremos enviar mediante correo electrónico no es un texto; sino un fichero binario, un programa, un gráfico, una animación, etc. En este caso o bien SMTP no debe cambiar las combinaciones de 0 y 1 bajo ninguna circunstancia, o creamos un sistema que haga que estos cambios sean reversibles.

En un principio, la solución adoptada para permitir este tipo de intercambio fue esta última. El procedimiento consistía en que el usuario que enviaba el fichero binario tenía que someterlo previamente a un proceso de codificación (decoded) que tenía como resultado el fichero original. El inconveniente de este procedimiento es que se convierte es una tarea tediosa de realizar; y hasta complicada, para algunos usuarios. La mejora vino de la mano de MIME.

\section{LOS ESTÁNDARES EN. INTERNET.}

Desarrollar aplicaciones para Internet implica atender a un conjunto de estándares amplios que permiten que distintas personas. de diferentes plataformas se comuniquen correctamente. Por ese motivo existen numerosas organizaciones y personas, de todo el mundo, que son responsables de mantener las especificaciones estándares para el mundo de Internet.

Los estándares se tienen que enfrentar a distintos herramientas para el desarrollo del software para Internet, etc. Por estos motivos y muchos otros, el establecimiento y mantenimiento de los estándares es una tarea de muchos y muy complicada.

En los siguientes puntos se hablarán sobre las organizaciones estandarizadas para Internet y sobre los estándares de Internet. es decir, los RFCs.

\section{BIBLIOGRAFÍA}

GREENFIELD, Joseph D

Practical digital design using ICs.

HUIDOBRO, José Manuel

Sistemas de Comunicación

TAVERNIER, C.

Modems: Técnica y realización 